\title{
Comparison of Japanese Nursing Students' Feeling of Children and Image of Medical Institutions Before and After a Pediatric Nursing Modules
}

\author{
Naomi Matsumori ${ }^{1}$, Ryoko Ito ${ }^{1}$, Yukiko Hyakuta ${ }^{2}$ \\ ${ }^{1}$ Department of Nursing, Faculty of Health and Welfare, Prefectural University of Hiroshima, Hiroshima, Japan \\ ${ }^{2}$ Graduate School of Comprehensive Scientific Research, Prefectural University of Hiroshima, Hiroshima, Japan
}

Email address:

matumori@pu-hiroshima.ac.jp (N. Matsumori)

\section{To cite this article:}

Naomi Matsumori, Ryoko Ito, Yukiko Hyakuta. Comparison of Japanese Nursing Students' Image of Children and Medical Institutions Before and After a Pediatric Nursing Modules. American Journal of Nursing Science. Vol. 4, No. 5, 2015, pp. 255-260.

doi: 10.11648/j.ajns.20150405.12

\begin{abstract}
The nursing students have fewer opportunities to come into contact with children due to the declining birth rate in Japan. The objective of this study was to clarify the changing of the feelings of children and the image of nursing students about the medical institutes of pediatric before and after a pediatric nursing modules. We also aimed to identify related issues in education of pediatric nursing that need to be addressed in Japanese nursing education in order to facilitate faculty development. Students who had taken a 4-year nursing course (244 nursing students from one university) were asked to rate items on the Affection for Babies Scale (ABS; Hanazawa, 1992) and a questionnaire on their image of hospitals (clean, scary, it seems tough, an unknown world, etc.) created by the authors before $2^{\text {nd }}$-year modules and after $3^{\text {rd }}$-year modules. Informed consent was obtained from all students who agreed to participate. Analysis of 217 valid responses of students who took the survey both before and after the course was conducted. In response to the question regarding contact with children before the $2^{\text {nd }}$-year modules, showing that more than $70 \%$ of students had limited contact with children. Approximately $60 \%$ of the students answered that they "consciously watched children" after the $3^{\text {rd }}$-year modules. There was no significant difference in the mean of ABS scores before and after the course. While this course evoked a general interest in children, additional measures are needed to develop a course tailored to students with strong avoidance feelings towards children. Students' image of hospitals as "scary" places and "an unknown world" therefore decreased, and answers of "it seems tough" and "I am unsure (how to interact with children)" increased as students' image of hospitals improved to "friendly and helpful" as a result of this course. This suggested that students need psychological support for times when they actually come into contact with children and to teach child health nursing with a good relationship between the mentor and mentee at Japanese nursing education.
\end{abstract}

Keywords: Nursing Students, Image of Children, the Medical Institutes of Pediatrics, Aging Society with a Declining Birthrate, Japanese Nursing Education

\section{Introduction}

Japan is facing a declining birth rate and an aging society. It has a total population of 127 million, total fertility rate of 1.41 (2012) and elderly person rate of 25.06\% (2013; OECD Health Data, 2014). Various measures and mentoring considerations are required in teaching pediatric nursing to nursing students, who have fewer opportunities to come into contact with children due to the declining birth rate.

Japanese nursing education system has only the general nursing qualification. Japan already had almost 80 institutes of university for bachelor of nursing in 2000 and currently has almost 250 institutes of university for bachelor of nursing in 2015. After the graduation, in most cases, if Japanese nurses work at a pediatric department, they will receive the specialized training for pediatric nursing. Regular of Japanese nursing education has more than 3,000 hours of lectures and practices for three years. In the case of our university, nursing course has four years education. In our department, students take a liberal arts module on development in their $1^{\text {st }}$-year, modules providing an introduction of pediatric nursing in their $2^{\text {nd }}$ and modules of 
specialized pediatric nursing in $3^{\text {rd }}$-years, and pediatric nursing practical training for 3 weeks in their $4^{\text {th }}$-year.

Students also take a seminar on care in daily life using doll model simulations in their $2^{\text {nd }}$-year, and a seminar on medical care using medical model simulations in their $3^{\text {rd }}$ year.

The undergraduate nursing students have definite, preconceived ideas as to the areas of nursing practice in which they would most like to work in the future. Student's explanations reflected a love of, and desire to work with, children, suggesting a relatively naive and uninformed view at the commencement of their course. In view of the problems experienced in the recruitment and retention of adequate numbers of pediatric nurses, there is an urgent need to promote a more realistic view of this area of practice [1].

Safadi et al. described nursing students' changing perception of nursing over 4 years of the nursing program. Student perceptions changed from lay altruistic beliefs of nursing to theoretical medical technological views of the profession denoting a theory-practice gap [2].

Wada et al. measured the Affection for Babies Scale (ABS; Hanazawa, 1992) of their nursing students in their $3^{\text {rd }}$ -year, focusing on the period during the maternal and pediatric nursing practicums. The approach feeling scores of the students after maternal nursing practicum were significantly higher than those of students after the pediatric nursing practicum [3][4]. Miyara et al. measured ABS of their nursing students in their $2^{\text {nd }}$-year before a pediatric nursing lectures, the score was affected by frequency of opportunities of contact with children. The students who have many opportunities of contact with children had the image of children concretely more than the students who have less opportunities [5]. Jitsuzaki et al. investigated the factors influencing the emotions of nursing student toward children in order to apply the results to their practical training, since the opportunity for contact with children has been decreasing in recent years due to the declining birth rate. The negative point for the concept of motherhood was significantly lower in the group that had finished nursing training in child and maternal care than in the group without such training [6].

We investigated about Japanese nursing students' image of children and medical institutions before and after pediatric nursing lectures of nursing university. Changing of each image seems as part of class evaluation of pediatric nursing in Aging Society with a Declining Birthrate in Japan. This study would become the grounds on bringing up nurses taking future child health nursing in the recruitment.

In this study, the results of a questionnaire on nursing students' image of children and hospitals were compared before and after taking a course in pediatric nursing. The students were surveyed as part of class evaluation and the findings were intended as reference material for student mentoring and class improvement. The objective of this study was to clarify the changing of the feelings of children and the image of nursing students about the medical institutes of pediatric before and after a pediatric nursing modules. We also aimed to identify related issues in education of pediatric nursing that need to be addressed in Japanese nursing education in order to facilitate faculty development.

\section{Methods and Participants}

Students who had taken a 4-year nursing course (244 nursing students from one university the research members are belonged) were asked to rate items on ABS and a questionnaire on their image of hospitals (clean, scary, it seems tough, an unknown world, etc.) created by the authors before $2^{\text {nd }}$-year modules and after $3^{\text {rd }}$-year modules [7].

\subsection{Questionnaire Design}

The questionnaire was designed by ABS and the image of medical institutes of pediatrics in Japan. ABS has two kinds of items, avoidance feeling score and approach feeling score, each have 14 items in the questionnaire. The ABS has good internal consistency and test-retest reliability [4]. The questionnaire about the image of medical institutes of pediatrics in Japan have 10 kinds of items, clean, reliable, friendly, hope, great, and tough, unknown world, scary, where I do not want to go, suffering. Items were rated on a 4-point scale from "strongly applies" to "does not apply" The image of medical institutes of pediatrics point the image of the place that you may practice in $4^{\text {th }}$-year. A pilot test $(n=60)$ was carried out to evaluate the questionnaire about the negative and positive image of medical institutes of pediatrics and the item consistency for the scale was calculated (Cronbach's $\alpha$ $=.84 \sim .65)$.

\subsection{Data Analysis}

Data were aggregated in Microsoft Excel (Microsoft Corporation, Santa Rosa, CA) and Chi-square tests and t-test were performed with a significance level of 0.05 (SPSS Ver. 19; IBM, Chicago, IL). The score for each of the 14 items measuring feelings about approaching children and evasive feelings (approach feelings score, avoidance feelings score) in $\mathrm{ABS}$ and the conflict index (score representing the degree of antagonism of both feelings $=$ avoidance feelings score $\div$ approach feelings score $\times 100$ ) were aggregated. Numerical values were rounded to the nearest hundredth for analysis. Students' comments were coded and classified in every similar meanings of contents by quantitative contents analysis.

\subsection{Ethical Considerations}

Students were informed of the purpose of the study, that participation was voluntary, that answers would have no effect on their years, and that the results may be published but no individuals would be personally identifiable. Informed consent was obtained from all students who agreed to participate. 


\section{Results}

\subsection{Participants}

Analysis of 217 valid responses of students who took the survey both before and after the course was conducted. The each serial numbers of the 2nd year responses and 3rd year responses were matches. 2nd year students are 19-23y $(\mathrm{Av}-19.52 \mathrm{y}), 3 \mathrm{rd}$ year students are 20-24y $(\mathrm{Av}=20.52 \mathrm{y})$.

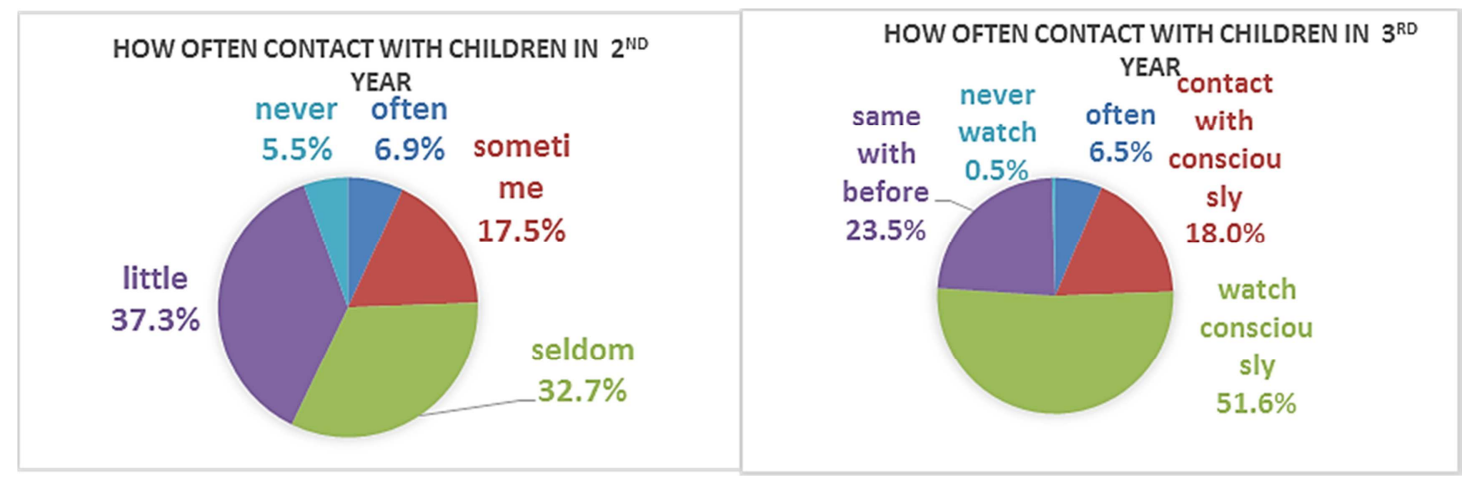

Figure 1. Changing consciousness of contact with children from 2nd-year to 3rd-year.

\subsection{Changing Consciousness of Children from $2^{\text {nd }}$-Year to $3^{\text {rd }}$-Year}

In response to the question regarding contact with children before the $2^{\text {nd }}$-year modules, $32.7 \%$ answered "seldom", $37.3 \%$ answered "little" and 5.5\% answered "never", showing that more than $70 \%$ of students had limited contact with children. Approximately $60 \%$ of the students answered that they "consciously watched children" after the $3^{\text {rd }}$-year modules.

\subsection{Compare with Affection Scale for Baby Between $2^{\text {nd }}$ Year and $3^{\text {rd }}$ Year}

There was no significant difference in the mean of ABS scores before and after the course by T-test, the approach feelings score, avoidance feelings score and conflict index increased from 26.7 to 27.1 , from 9.3 to 9.7 , and from 37.0 to 39.1 , respectively.

The mean conflict index of students who answered that their contact with children was the "same as before" after the $3^{\text {rd }}$-year modules was 51.9 , which was higher than the index of 35.1 for students who answered differently $(\mathrm{p}<0.05)$. Of the students who answered the "same as before", $75.6 \%$ had continued to have little contact with children and they predominantly had a high conflict index with avoidance feelings towards children. While this course evoked a general interest in children, additional measures are needed to develop a course tailored to students with strong avoidance feelings towards children.

\subsection{Changing Image of Medical Institutes of Children from $2^{\text {nd }}$ Year to $3^{\text {rd }}$ Year}

The proportion of students who answered with "strongly applies" in response to "scary" and an "unknown world" among the items for image of hospitals decreased from $29.0 \%$ and $20.7 \%$, respectively, before the course, to $3.7 \%$ and $9.7 \%$, respectively, after the course $(p<0.05, p<0.01)$. For "friendly and helpful" and "it seems tough", the proportion increased from $14.8 \%$ and $19.8 \%$, respectively, to $33.2 \%$ and $56.7 \%$, respectively $(\mathrm{p}<0.01, \mathrm{p}<0.01)$.

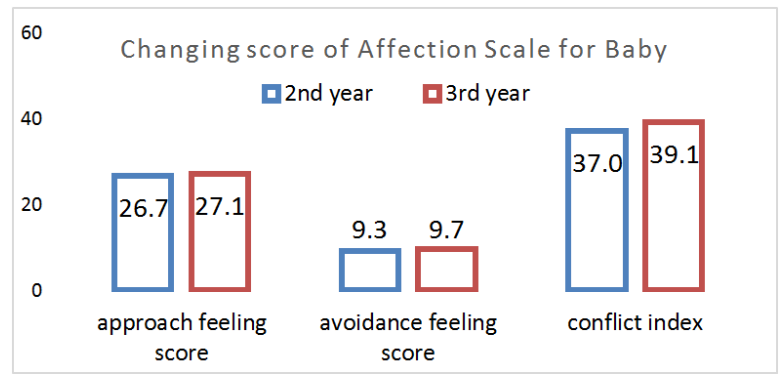

Figure 2. Score of Affection Scale for Baby.

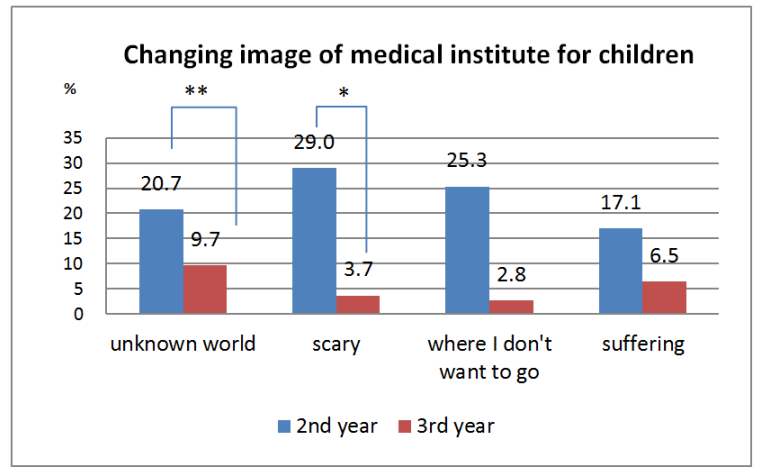

Figure 3. Changing negative image of medical institute for children (* $p<0.05, * * p<0.01)$.

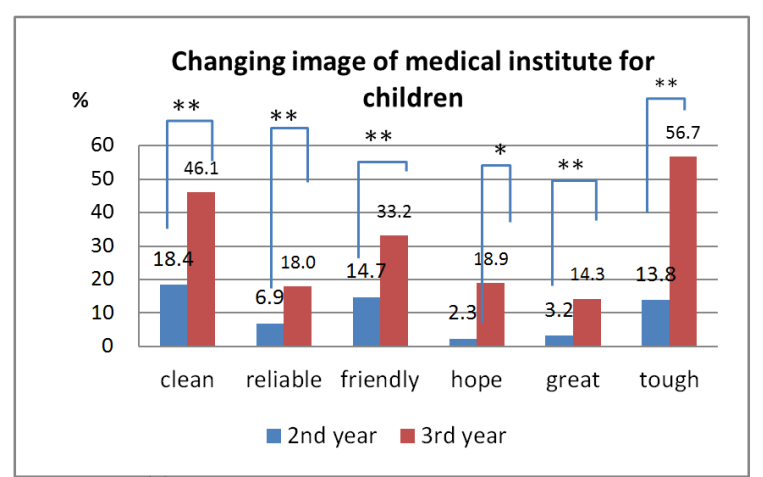

Figure 4. Changing positive image of medical institute for children $(* * p<0.01)$. 


\subsection{Changing Open-Ended Responses of Medical Institutes of Children from Before and After the Course}

Among students' comments, expressions such as "I didn't like it" and "scary" were often used before taking the course to describe the image of hospitals from past visits. However, after taking the course, expressions such as "it seems tough" and "I am unsure (how to interact with children)" increased as students adopted a nurse's perspective. Students' image of hospitals as "scary" places and an "unknown world" therefore decreased, and answers of "it seems tough" and "I am unsure (how to interact with children)" increased as students' image of hospitals improved to "friendly and helpful" as a result of this course. (Table 1.)

Table 1. Open-ended responses (main part of responses).

\begin{tabular}{lll}
\hline $\mathbf{2}^{\text {nd }}$ year & $\mathbf{n}$ & $\mathbf{3}^{\text {rd }}$ year \\
\hline I didn't like hospital and injection. & 51 & It seems tough. \\
Hospital was scary. & 43 & I feel difficult. \\
It seems tough. & 22 & I feel scary. \\
It seems difficult. & 15 & I feel anxious about caring for children. \\
I feel anxious. & 9 & \\
Nurses were friendly. & 27 & I like children. \\
It is important that nurses have the same position as children. & 10 & I am looking forward to having nursing practice at a pediatric department. \\
I am interested in a pediatric nursing. & 3 & I have positive image of pediatric department. \\
& & It's pretty, friendly. \\
& & I am interested in pediatric nursing. \\
\hline
\end{tabular}

\section{Discussion}

In the case of 20-24y Japanese unmarried women, an average of approach feeling score is 24.6 , an average of avoidance feeling score is 9.0 , and conflict index is 38.3 . In the case of Japanese female college students who contact with children often, an average of approach feeling score is 27.9, an average of avoidance feeling score is 9.7, and conflict index is unclear [2]. The average of score before $2^{\text {nd }}$-year module is higher than an average of 20-24y Japanese unmarried women, the average of score after $3^{\text {rd }}$-year module is similar to the average of Japanese female college students who contact with children often. In the case of another $3^{\text {rd }}$-year nursing students, conflict index is 35.6. In another case of $3^{\text {rd }}$-year nursery school students, conflict index is $34.0[8]$. The approach score of students who have good image for children is higher, and avoidance score, conflict index is lower. But students have ambivalent image of childcare, "care is delightful" and "care is tough". The score of the nursing students is lower than the nursery school students, because the nursery school students work with children or infants only, but the Japanese nursing students work with all age people. The approach score of who contact with children often in the past is higher. The approach score of who have positive relationship with parents is higher. It is important to effect positive relationship with parents that students have an interest of declining birth rate [9]. It seems effective that students have opportunities of understanding a good parenting and contacting with children. In the case of $3^{\text {rd }}$-year nursing students before the practice at NICU, an average of approach feeling score is 26.1 , an average of avoidance feeling score is 9.4, and conflict index is 34.8. Same nursing students after the practice at NICU, an average of approach feeling score is 23.4 , an average of avoidance feeling score is 9.3, and conflict index is 40.6. After the practice of NICU the approach feeling score is lower and the avoidance score and conflict index is higher than before practice. Another $3^{\text {rd }}$-year nursing students before the practice at NICU, an average of approach feeling score is 24.6, an average of avoidance feeling score is 10.0 , and conflict index is 39.3. But in the case of same nursing students after the practice at NICU with conference participating nursing teacher when final date of practice, an average of approach feeling score is 22.2, an average of avoidance feeling score is 6.9 , and conflict index is 31.3 . It seems good effect on emotion that the nursing students have a conference with participating the nursing teacher on final date of nursing practice [10].

Glasper et al. investigated student nurses' perceptions of the process of undergoing a program of education leading to registration as a children's nurse. The factors which helped students most in their quest to become children's nurses included: the delivery of specialist lectures from child branch nurse lecturers, having good clinical placements with mentors who want to support students, and having the support of friends and family. An important factor was the desire to become a good children's nurse and wanting to work with children. Factors which hindered students included: having unsupportive mentors who misjudge student abilities, lack of academic resources including library reading materials, too many students in each clinical area [11]. The experiences of student nurses at a summer residential camp for children with diabetes were examined using a service-learning framework. Camp positively increased knowledge of diabetes in the nursing students. Reflective journals identified themes of anxiety, fatigue, responsibility, and increased confidence in the nursing student, while developing empathy for the lifestyle of children with diabetes [12]. Student placements in the pediatric intensive care unit (PICU) have a number of benefits including the recruitment of staff to this specialty, students' learning of important observational skills and reinforcing the knowledge and skills of existing staff. However, the combination of critically ill children and large amounts of complex equipment can be 
daunting for the student nurse commencing a clinical placement in PICU. Careful induction, ongoing mentoring and opportunities to explore issues help to overcome students' fears of being unable to cope, and support the application of theory to practice in this challenging environment [13]. Muleya et al. studied what are the perceptions and experiences of nursing and midwifery students regarding mentorship during clinical placement by a systematic review. Mentorship has been the model adopted by many countries to support learning and assessment of students in the clinical placement. The findings suggest that there are still gaps within the mentorship program that could have an impact on the students' learning experiences during clinical placement. From the themes identified which include need for feedback, hands on practice, continuity of mentorship and mentor-mentee relationship, the reviewers concluded that such areas of mentorship require attention in order to benefit the students. It is also clear that mentorship will be beneficial to students if a good relationship is established between the mentor and mentee, as this is the beginning of the experience. All faculty members should be willing to support students in learning for them to develop the knowledge, skill and attitudes that are necessary to their learning [14]. Mentors, buddies, qualified nurses and other healthcare professionals shape the practice experiences of nursing students and change their perceptions on how care is delivered in the healthcare environment. Based on these experiences and perceptions, the student will decide whether to continue with a career in nursing. Once qualified, nurses cannot be expected to know everything. Clinical teams must be supportive of staff learning needs, acknowledging that relationships with mentors, supervisors and other staff will affect an individual's ability to fit in, to ask questions and to feel safe [15]. The certified nurse survey respondents had self-reported high levels of job satisfaction and indicated that relationships with colleagues and a supportive work environment were very important to their levels of job satisfaction [16].Rhodes conduct an in-depth investigation into the impact of user involvement on student learning and subsequent influence on practice as a qualified nurse. Narratives were collected from a children's nursing student on completion of her 3-year nurse education program and again after practicing as a qualified children's nurse for 1 year. Taking part in the research enabled the participant to consider and reflect on her experience of user involvement in her education and training. The findings identified central themes of authenticity, knowledge of self, resilience and coping, professional relationships, personalization of care, and influence on practice. This demonstrates transformative learning and support to practice, with preparation for situations and ideas on how to respond with empathy and compassion [17].

$3^{\text {rd }}$-year students who answered "same with before" has no change, conflict index average is higher than out of them, and avoidance feeling score tend higher. It is need to provide them a variety of devise and guidance in the module of the pediatric nursing to change their feeling to approach to child. $2^{\text {nd }}$-year students had responses, like "scare", "unknown world" as pre-nurse, $3^{\text {rd }}$-year respondents had responses, "friendly", and "tough", " anxiety of care for children" to be nurses. This suggested that students need psychological support and a good relationship between the mentor and mentee, as the beginning of the experience when they actually come into contact with children in a course in pediatric nursing.

\section{Conclusion}

Analysis of 217 valid responses of students who took the survey both before and after the course was conducted. In response to the question regarding contact with children before the $2^{\text {nd }}$-year modules, showing that more than $70 \%$ of students had limited contact with children. Approximately $60 \%$ of the students answered that they "consciously watched children" after the $3{ }^{\text {rd }}$-year modules. There was no significant difference in the mean of ABS scores before and after the course, the approach feelings score, avoidance feelings score and conflict index, respectively. The mean conflict index of students who answered that their contact with children was the "same as before" after the $3^{\text {rd }}$-year modules was higher than the index of students who answered differently $(\mathrm{p}<0.05)$. Of the students who answered the "same as before", $75.6 \%$ had continued to have little contact with children and they predominantly had a high conflict index with avoidance feelings towards children. While this course evoked a general interest in children, additional measures are needed to develop a course tailored to students with strong avoidance feelings towards children. It is suggested that we need to assess the image of students about children, medical situation, and to provide mental support for students to contact with children and to teach child health nursing with a good relationship at Japanese nursing education. The limit of this study was to search at only one university before the practice of pediatric institutes. It will be necessary to plan generalization to increase target facilities, after the nursing practice in future.

\section{Acknowledgements}

I would like to thank all the participants who assisted with data collection.

\section{References}

[1] Happell, B.M. (2000) Love Is All You Need"? Student Nurses' Interest in Working with Children. Journal of the Society of Pediatric Nurses, 5(4), 167-173.

[2] Safadi, R.R., Saleh, M.Y., N., Nassar, O.S., Amre, H.M., and Froelicher, E.S. (2011) Nursing students' perceptions of nursing: a descriptive study of four cohorts. International Nursing Review 58, 420-427.

[3] Wada, K., Ohkubo, A. (2002) Changes in Maternal Affect Toward Babies of Nursing Students through Maternal and Pediatric Nursing Practicums (Japanese), Journal of Niigata Prefectural College of Nursing, 8, 11-16. 
[4] Hanazawa, S. (1992) Development of Maternal Feeling (Japanese), Maternal Psychology, Igakusyoin, 61-91.

[5] Miyara, J., and Jintoku, N. (2013) Nursing Students’ Emotions Childcare - Comparison and Readiness for Parenthood before Pediatric Nursing Study (Japanese). Bulletin of Faculty of Nursing of Chukyo Gakuin University, 3(1), 29-41.

[6] Jitsuzaki, M., Anan, A., Fukuzawa, Y., Kawaguchi, S., and Kanayama, M. (2006) Factors Influencing Student Nurses' Motherhood Emotions toward Children and their Concept of Motherhood (Japanese). Journal of University of Occupational and Environmental Health, 28 (3), 295-304.

[7] Matsumori, N. (2012) The change of nursing-student's image about children and children's medical institutes; before and after the lecture of child health nursing (Japanese). The 2 2nd Conference of Japanese Society of Child Health Nursing, Abstract, 180.

[8] Ishimatsu, N., Eto, S. and Yamamoto, S. (2004) University Students Images and Emotions Childcare : Comparison of the nursing department students and other department students (Japanese), Japan Red cross Kyusyu international college of nursing intramural research report 2, 145-154.

[9] Matsuoka, T., Horiuchi, H. and Yamanaka, A., Ito, T. (2000) Consciousness of male-female bachelor students becoming parents (Japanese), Journal of Japan society of Maternal Health, 41(4), 398-404.

[10] Ohkubo, A., Wada, K. and Akiyama, K. (2001) A Study of the Effect of Post-Conference on students' Maternal Affect
Toward Babies While Engaged in a Clinical Rotation in the Neonatal Intensive Care Unit (NICU) (Japanese), Journal of Niigata Prefectural College of Nursing, 7, 3-7.

[11] Glasper, A., Richardson, J. and Whiting, M. (2006) The highs and lows of learning to be a children's nurse. Paediatric Nursing, 18(6), 22-26.

[12] Vogt, M.A., Chavez, R. and Schaffner, B. (2011) Baccalaureate nursing student experiences at a camp for children with diabetes: the impact of a service-learning model. Pediatric Nursing, 37 (2), 69-73.

[13] Cochrane, J., Heron, A. and Lawlor, K. (2008) Reflections on student nurse placements in the PICU. Paediatric Nursing, 20(1), 26-28.

[14] Muleya, C.M., Marshall, J. and Ashwin, C. (2015) Nursing and Midwifery Students' Perception and Experiences of Mentorship: A Systematic Review, Open Journal of Nursing, 2015, 5, 571-586. http://dx.doi.org/10.4236/ojn.2015.56061

[15] Pearson, H. (2009) Transition from nursing student to staff nurse: a personal reflection. Paediatric Nursing, 21 (3), 30-32.

[16] Wyatt, J. and Harrison, M. (2010) Certified pediatric nurses' perceptions of job satisfaction. Pediatric Nursing, 36 (4), 205-208.

[17] Rhodes C.A. (2013) Service user involvement in pre-registration children's nursing education: the impact and influence on practice: a case study on the student perspective. Issues in Comprehensive Pediatric Nursing, 36 (4), 291-308. 